\title{
Legal networks: visualising the violence of the law
}

\author{
Jeremy Pilcher \\ Lancaster University \\ Department of Media, Film \& Cultural Studies \\ County South, Lancaster University \\ Bailrigg, Lancaster \\ LA1 4YD \\ j.pilcher@lancaster.ac.uk
}

\begin{abstract}
Internet art that employs data visualisation techniques may be engaged with both in terms of the data used and also the interface to that data. Such an approach allows it to be understood as opening the possibility of an awareness of the contingency of the way any given community is constructed. The focus is shifted away from understanding data visualisation art as providing a transparent representation of reality. This is exemplified in the work They Rule which, approached in these terms, invites an engagement with the law's role in enabling networks of powerful people to be constructed. They Rule opens the possibility of perceiving the law's violence in the way that it asserts the authority of enabling and enforcing the existence of such connections. An awareness of the constructed nature of legal networks opens the law to the possibility of change by those it excludes.
\end{abstract}

Internet art. Law. Legal networks. Data visualisation. Network diagrams. They Rule. Jacques Derrida.

\section{INTRODUCTION}

Data visualisation techniques have been used by artists as a means to critique society and in particular capitalism. The possibilities for interaction with, and the malleability of, data on the internet makes it an effective site for this as practice. Such art has commonly been regarded as a means to reduce an overwhelming amount of data to a meaningful representation. However, in this article and inspired in particular by the work of Jacques Derrida, I understand art as opening the possibility of an awareness of the contingency of every form of community. I explore data visualisation in art in such terms through the online work They Rule by Josh On. I argue that it may be understood to invite an understanding of the violence of the law as exemplified in the legal formation of corporations and interconnecting networks of company directors.

\section{ACTIVIST INTERNET ART}

The internet has been described as having been colonised by corporations and e-commerce. Art that exists online has been created to critique the 'model of consumerism' that is antithetical to 'the ability to cite freely, to purloin images that are salient within the general culture, to pursue a conversation without vetting by lawyers'
(Stallabrass, 2003). This model has brought into question the perception of the net as a place that provides a space in which the influence of established institutions and networks of power may be undermined by means of 'immediate access to and transparency of data' (Ibid, p. 204). Some internet art has provided a direct challenge to laws, such as those that protect copyright, which are used by corporations to assert control over the internet (Greene, 2004; Paul, 2003; Stallabrass, 2003). This challenge has been characterised as being 'crucial to democracy and free speech' (Stallabrass, 2003, p. 104).

\subsection{Data visualisation in Art}

One means of subverting the use of the internet as a 'mere marketing tool that turns us into transparent customers' (Paul, 2003, p. 205) is the visualisation of data. It is common for the practice of data visualisation to be understood in terms of the way in which the 'informational chaos' of data online is visually transformed into orderly forms that enable patterns to be seen in what otherwise appear to be apparently random data sets (Manovich, 2002). Approached in such terms the distinction between information and data is central to the technique. As Brett Stalbaum has pointed out, although the terms 'data' and 'information' are 
often conflated, data may be defined as being raw facts; whereas information is obtained by processing data (Stalbaum, 2006). It is the reductive effect of data visualisation that leads Stalbaum to discuss such art in terms of the sublime and the experience of beauty. Beauty is associated with information in that it is involves clarity and transparency. By contrast the sublime overwhelms the viewer with data but nevertheless results in the viewer's senses being 'mobilized in a special kind of cognition that allows them to carry on with the formation of an understanding' (Stalbaum, 2006).

This approach provides a basis to engage with why the practice of data visualisation, and in particular the use of network diagrams, is used to critique capitalism. As Jean-François Lyotard identified: 'there is even something of the sublime in the capitalist economy' with its regulation by the idea of 'infinite wealth or power' (Lyotard, 1991, p. 105). In such a context 'the political nature of data' becomes apparent (Griffis, 2004). This is exemplified by Hans Haacke's social system works, of which Shapolsky et al. Manhattan Real Estate Holdings, a Real-Time Social System, as of May 1, 1971 is notorious because the Guggenheim refused to allow it to be exhibited. Haacke managed to make a series of bland photographs, charts and network diagrams about the real estate holdings of slum tenements in New York so provocative the museum stated it was concerned legal action for libel would be brought by those referred to in the work. More recently Mark Lombardi's pencil network diagrams of crime and conspiracy networks have been described as combining the:

feeling of discovering new beauty with a political undertone - the idea that the world has become less hierarchical but, on the other hand more highly networked (Bednarzek, 2005, p. 20).

Understood in terms of the creation of transparent meaning out of opaque data it may be argued that digital online network visualisation strengthens the critical potential of network art.

There is a paradigmatic shift between the computer database and other more traditional collections of documents. The database allows millions of records to be quickly accessed, sorted, and reorganised. It may also contain different media types, and it allows the multiple indexing of data (Manovich, 2001, p. 214). Moreover, because the data is in digital form it is susceptible to being manipulated and interacted with very rapidly by users. All of these characteristics have been employed by internet artists, of which a good example is the work They Rule by Josh On.

\subsection{They Rule}

They Rule provides the viewer with the opportunity to interact with data about some major institutions and the boards of directors of companies that were in the top 500 companies in the United States of America. It has been described as:

\begin{abstract}
one of those rare sites where the content material is actually so interesting that it matches the design. If only the economic realities it depicts were as transparent and intuitive as its navigational structure, this would be a more benevolent world (Johnstone, 2005).
\end{abstract}

The work won the Golden Nica award at the Ars Electronica Festival in 2002 for 'Net Excellence' and has been exhibited at various high profile digital art festivals including among others, DEAF03 organised by the Dutch V2 centre and at the Whitney Biennial (Derivart, 2006).

They Rule is substantially based on data that is legally required to be made public and filed with a government agency, the United States Securities and Exchange Commission ('SEC'). There are in fact two versions of the work, one based on SEC data from 2001 and the other from 2004. As has been pointed out the work exploits the same principle as the database used against Slobodan Milosevic at The Hague: when enough information is gathered together it is possible to find connections that might not otherwise be apparent (Ippolito, 2002, p. 496). The work enables networks to be identified from the data by employing 'the features of networked technologies, such as dynamic mapping, hyperlinking, and instant searches' (Whitney Artport, 2002).

They Rule enables users to trace connections between company directors and so discover, for example, that 'the members of the boards for the so-called competitors Coke and Pepsi actually sit together on the board of a third corporation, Bristol Myers Squibb' (Ippolito, 2002, p. 496). Each of the companies included in the databases is represented by an icon of a company board table surrounded by avatars representing the board members. There are various sizes of the avatars for directors. As the 'Help with They Rule' section on the work's website explains the larger a director's avatar the more company boards are sat on by that director. Clicking on individual directors reveals the other members of the boards on which that director sits. As users move through this process the connections between directors who sit on different company boards become apparent and network diagrams start to form. The interface the work provides to its databases also enables the visual explorations of 'the interwoven brachiations and power structures' to be saved (Bednarzek, 2005, p. 19). 
Commentary on They Rule tends to focus on its economic and political relevance and the extent to which there are interconnected networks of directors who control what is supposed to be a free-market economy, and so are able to influence society. There is little discussion of its legal aspects. The networks visually depict relationships that only exist by reason of the law. Companies, and concomitantly the role of directors of such organisations, are brought into being by reason of the operation of the law. Corporations benefit from the law recognising that they have a number of advantageous features. In brief, companies are treated as individual legal entities. The liability of a shareholder in companies is limited to the sum of money invested by that person. A company potentially has immortality in that it can continue to trade indefinitely. These and other characteristics make companies powerful entities that are not infrequently criticised for neglecting their social responsibilities in favour of making profits.

\subsection{U.S. Securities and Exchange Commission}

Companies are regulated specifically in order to protect investors and, more widely, the economy. The SEC's mission is to 'protect investors, maintain fair, orderly, and efficient markets, and facilitate capital formation'. As its website states the SEC is responsible for enforcing and regulating the laws and rules that govern the securities industry in the United States and these:

derive from a simple and straightforward concept: all investors, whether large institutions or private individuals, should have access to certain basic facts about an investment prior to buying it, and so long as they hold it (SEC: 'What We Do').

The SEC states that it considers the best way for investors to protect their money is to do research and ask questions. In order to facilitate this SEC operates a database, called EDGAR.

The SEC website provides access to the EDGAR database of disclosure documents that public companies are required to file. It is regularly updated and enhanced. As its website describes SEC is committed to transforming the EDGAR database from 'a form-based electronic filing cabinet to a dynamic real-time search tool with interactive capabilities using XBRL computer language' (SEC: 'Quick Edgar Tutorial'). Although They Rule is acknowledged as an activist work it may be regarded as expressing a common concern with the SEC. The work states on its website: 'please just see They Rule as a launch pad for investigations and not the definitive representation of reality' (On, 2004). Approached from either perspective They Rule has a number of significant limitations.

\subsection{They Rule's Limitations}

The EDGAR database has a number of advantages over They Rule in terms of ensuring the transparent operation of companies. As mentioned on the art work's site companies change name, or cease trading altogether and the composition of boards of directors is continually in flux. Yet it is acknowledged:

They Rule is NOT a Live database of board members and companies. That information changes constantly. I hope to update the database annually, and try to ensure that the links are accurate at the time of launch. Please inform me if you find a connection that was never true (On, 2004).

The EDGAR database is much more up to date than They Rule because companies have statutory obligations to file information within certain specified time frames.

Moreover, while the amount of data in the work's databases may be large it is also highly selective and, even considered in terms of connections between directors, very limited. This may be illustrated by reference to the way in which They Rule does not provide any representation of the ownership of shares in corporations. This is as central, if not more so, to the issue of who 'rules' the global capitalist economy as the connections between company boards through common directorships. There are extensive networks of companies connected by reason of the common ownership of shares by a vast range of different people and corporate entities.

These limitations mean that for me the claims made for the work's subversive nature need to be revisited. Given the dated nature of the data it may be said that what They Rule uncovered as objectionable is that the legal system allowed companies that were competitors to have common directors on their boards. Approached in terms of the way it made reality more transparent its continued relevance would then seem to be predicated largely on the assumption that this situation continues to apply and be permitted by law.

This connection between directors is readily conceptualised even without the diagrams that They Rule enables users to construct. Once somebody is interested to know what boards a given director sits on it is relatively straightforward to use information filed with SEC to obtain the relevant up to date information. I acknowledge that the work enables a very specific set of historical connections between directors and the boards of companies on which they sit to be perceived more easily than would have been the case using the 
SEC archive. However, it seems to me that if They Rule is simply understood in terms of the way it allows people to become aware of relationships between the boards of directors of competitor companies then it may be subjected to a general critique made by Lev Manovich of new media art that employs data visualisation.

\subsection{A Critique of Data Visualisation}

Manovich observes that one way to engage with art that employs data visualisation is to examine the reason why an artist has chosen to visualise data in a certain way. He suggests that data mapping new media projects which are "driven by the rational impulse to make sense out of our complex world' tend to miss the opportunity to 'show us other realities embedded in our own, to show us the ambiguity always present in our perception and experience' (Manovich, 2002). Manovich calls for work that does more than:

how to map some abstract and impersonal data into something meaningful and beautiful economists, graphic designers, and scientists are already doing this quite well (Manovich, 2002)

He suggests that data visualisation artists should engage with the portrayal of what it means to live 'immersed in data'. It is possible to illustrate Manovich's concerns in the context of They Rule by comparing it with a joint university-government project called Whosfundingwho that was developed to help visualise data about campaign funding in San Francisco.

\subsection{Whosfundingwho}

David Wolber describes how the project takes:

raw data supplied from the Ethics commission, builds a relational database from it, then displays the data in forms that allow a user to easily view campaign activity and funding trails (Wolber, 2006, p. 29)

The aim was to allow users to 'do what Deep throat suggested to Woodward and Bernstein in the Watergate investigation: "follow the money" '. Two methods are provided for the navigation of such trails. One of them provides a 'graph view that shows entities and relationships with multiple degrees of separation'. This graph not only 'induces the biggest 'aha!' reaction from those that have viewed it' (Wolber, 2006, p. 33) it is also strikingly similar in visual appearance to many of the images that have been generated in They Rule. Approached in terms of its ability to make an underlying reality more apparent it might seem that there is little to distinguish They Rule as art from investigative projects such as Whosfundingwho, or authorised databases such as EDGAR. Yet it seems to me that the work does have a greater impact than simply providing a more transparent, albeit dated, representation of networks of company directors.

\section{ART AND THE VIOLENCE OF THE LAW}

To approach They Rule only as a truthful representation of some underlying reality is to place limits on how it is engaged with as art. In the work Non-relational Aesthetics Charlie Gere disagrees with arguments that art that employs digital technologies may contribute to a move toward a more transparent and cooperative social order. As Jacques Derrida argues in Limited Inc communication, whether by means of real-time technologies or not, is fissured from its inception by iterability (Derrida, 1988). In order for data to have meaning it must be able to be to be repeated in a different context. The iterability of data does not simply refer to its repetition. Data may have meaning because from its inception it differs in space, and is deferred in terms of time, from other data (Derrida, 1988, p. 70). I argue that it is this iterability that enables art to employ data in such a way as to invite it to be detached or loosened from its function of referring to reality. Art invites the focus to be directed toward the way in which the data is employed in the work itself (Miller, 2001; Attridge, 2004). Adopting such an approach I agree with Charlie Gere's conclusion that that art may bring about an awareness of the 'contingency of every form of community in the light of our separateness and singularity' (Gere \& Corris, 2008, p. 21). It is in this way that I understand art may have the force to critique the legal system. As Richard Beardsworth points out everything, including institutions and disciplines, is subject to iterability (Beardsworth, 1996, p.18). This iterability means they are open to change by being differently constructed.

Approached in these terms I suggest that They Rule may be understood to provide a way to engage with the iterability of law that it seems to me tends to be disavowed when the emphasis is on understanding it as providing transparent visualisations. My argument starts by proposing that loosened from an approach by which it is understood in terms of revealing a specific underlying reality They Rule becomes an invitation to engage with a bind, or aporia, in which every legal system is entangled. This aporia stems from the fact that necessarily all laws are applied at a time that is different from that at which they were formulated and brought into being. It follows that laws will need to be applied in quite specific individual situations that cannot be anticipated. Yet, at the same time the laws are also required to be sufficiently general so as to allow them to be 
enforced equally and in a way that is not arbitrary (Sokoloff, 2005, p. 342). The violence of the law is in the way it asserts the authority to demarcate what the exception(s) to it will be by determining what is generally acceptable.

The more established and general laws are the more apparent become the difficulties associated with trying to reconcile the general with the particular. As Derrida points out 'Each case is other, each decision is different and requires an absolutely unique interpretation, which no existing, coded rule, can or ought to guarantee absolutely' (Derrida, 1990, p. 961). Ultimately it is impossible for the universality of laws to be maintained given the need for decisions to be made as to the legal merits of individual cases. Exceptions will always need to be made in an attempt to give effect to justice in specific circumstances. It seems to me that They Rule may be understood to open the opportunity of an engagement with this aporia. It invites users to reflect on the (im)possibility of a legal system that is sufficiently general so as to equally apply to all whilst at the same time being able to adjust to specific circumstances as they arise over time.

\subsection{Interfacing with Data}

My argument as to how They Rule may open such an engagement starts by suggesting that the work is as much about how data is navigated as it is about the data from which meaning is sought to be extracted. I turn to Manovich's work in which he discusses the relationship between the data in a database and the interface provided to that data. $\mathrm{He}$ has argued the process of rendering large amounts of data into meaningful information is a product of the interface provided to users of the database. As he points out different interfaces provided to access the same data may translate the database into very different user experiences (Manovich, 2001, p. 181). The possibilities available for interaction with data are not only limited by the nature and the extent of the data that is entered but equally importantly by the way in which the interaction with the data is mediated through an interface. It is possible to construct a narrative by means of the interface by using it to create a cause-and-effect trajectory of seemingly unordered items. Approached in these terms narrative in new media objects is a function of the interface that is provided to data.

Manovich suggests that:

database and narrative are natural enemies. Competing for the same territory of human culture, each claims an exclusive right to make meaning out of the world (Manovich, 2001, p. 225).
However, database and narrative are not mutually exclusive (Paul, 2007, p. 100). Each new media work may be understood as combining both database and narrative to varying degrees somewhere along a spectrum with the respective aspects at either extreme. To a certain extent it is possible to understand the relationship between the SEC's website and They Rule in these terms. As already mentioned the art work is based on information filed with the SEC. However, my argument is that where the SEC presents itself as the univocal authorised source of data about corporations in the United States They Rule encourages users to reflect on how the ways in which the law is presented and accessed affects the way the law is understood. They Rule may be understood as revealing the extent to which the meaning of the legal system depends on the narratives that we are allowed to construct (by reason of the way in which data is archived), and not only specific relationships that are formed by reason of the existence of given laws.

\subsection{The Challenge of They Rule}

Those aspects of They Rule that make it weak as a representation of legal networks have the effect of directing attention to the way in which narratives drawn through data are constructed as a function of the interface. As I have already noted the databases employed by the two versions of the work are fixed and accordingly many of the connections it is possible to identify by using They Rule are likely to be out of date. Moreover, the concept underlying the visualisations, which is that a director may sit on more than one board of directors including those of competitor companies, is a straightforward link to be identified. It seems to me the work's significance lies more with the way in which the visually realised exploration of a stable database allows users to reflect on the process of manipulating data to form different network diagrams.

As users click on the avatars for directors on each company board there is no guarantee that connections between companies by way of common directors will be revealed. The screen quickly becomes cluttered with data after expanding a few companies' boards and directors with no contacts between the companies selected to be searched need to be deleted from the screen. Users are more or less compelled to be selective about the data that remains on screen for the work to function effectively. Furthermore, in the event that users then want the avatars to appear in the form of a visually appealing diagram the directors and board tables that remain have to be moved around the screen until the desired pattern for the network is achieved. The end result will not be available in the future unless a decision is made to 
save the diagram that has been constructed. In the process the work invites its users to become aware of the selection and organisation involved in finding and making meaning available from data.

Although there are many fascinating diagrams saved on They Rule in fact many investigations using the work do not result in establishing the existence of striking network connections. They Rule does not reveal that companies will have boards of directors that are interlinked. It enables people to realise that companies may be connected in this way. Moreover, They Rule draws attention to the way in which this meaning of data is constructed. The likelihood of constructing a diagram with clear and visually elegant connections is improved by employing knowledge not in fact available from the work itself. They Rule explicitly invites users to search elsewhere on the web. Of course this may take place whilst a diagram is being formed and so assist in its construction, or it may occur once a visualisation has been completed. It seems to me that by directing users' attention to additional sources of information encourages further reflection on the extent to which the meanings constructed from data in an archive may be arrived at only by reason of pre-existing knowledge or supplementing an archive's database.

They Rule invites thought to be given to the way in which the uses of digital technologies enabled by database interfaces affect data manipulation and the construction of meaning from that process. As such the work invites critical questions to be asked about both the network diagrams and the data underlying the images of networks. By contrast an authorised database, such as EDGAR, may present as a given the sort of meanings that may be obtained from the data the law requires to be made available. In the process the information obtained can seem to be a natural, almost inevitable, result. My argument is that the force of They Rule stems from the way it encourages users appreciate that perceptions of legal structures and relationships, such as companies and the connections between directors, are constructions arrived at by manipulating what might be thought of as neutral data. In fact I go a step further and suggest that They Rule opens the possibility that users will appreciate that the law, understood in its more general sense as itself a system, is also the result of a process of construction.

At this point I return to the aporia of the law I referred to earlier. I suggest that the process of either constructing different networks, or browsing through diagrams created previously, invites users to reflect on the existence of an underlying system that enables companies to exist and permits interconnecting boards. As I mentioned at the beginning of this paper companies are entities created and recognised by legal systems. Abstract company and related areas of law are not alone sufficient to account for legally formed individual companies, nor the specific connections that are created as between the directors of any given corporations. On the other hand the continual exploration of individual companies and networks of directors will only ever provide specific manifestations of what the law is at any given point in time and place. I suggest the work may be understood to invite people to consider whether it would be possible to frame laws that always prevented competing companies from having common directors but that would also allow for exceptions to be made in circumstances where it was fair and reasonable in given specific cases. In short it seems to me that They Rule may be understood to exemplify the aporia of the law.

\subsection{Before The Law}

They Rule allows an engagement with what Derrida has called the law of the law. As Douzinas and Gearey explain in Critical Jurisprudence this law is that:

\footnotetext{
The law remains temporally and spatially deferred. Law's secret, its essence and principle is always one door further away, there is always one more guard or judge to persuade (Douzinas \& Gearey, 2005, p. 357).
}

This comment was made in relation to Derrida's reading of the tale told by Franz Kafka, Before the Law. The work was published as both a short story of the same name, and as part of the novel The Trial. Very briefly, the story concerns the encounter between a man from the country and the law. The man comes to the law, but when he asks to be admitted by the doorkeeper he is told to wait. The man spends his entire life before the door awaiting admission to the law. Shortly before the peasant's death he is told by the doorkeeper that the door was meant only for him and that now the door will be closed for good.

At no stage does the guard physically prevent the peasant from entering the doorway, but rather he suggests that the door is only one of many, all of which are guarded by other more powerful doorkeepers. The law is before the man but is not present; it forever recedes to some other place and time. That is to say the law is iterable and as such is necessarily subject to temporal deferrals and spatial differentiations. As mentioned earlier, unless an institution is iterable it cannot have meaning in different contexts, and it this very iterability that opens it to the possibility of change. Before the Law may be understood to be a fable about the way in which, in order for the law to be enforceable, it must be repeatable or more precisely, iterable. It 
seems to me that users of They Rule are faced with a situation similar to that in Before The Law. They may continue to trace diagrams looking for interconnecting directorships without coming any closer to (an understanding of) the law that lies behind and authorises the existence of each network.

It is because the law is iterable that it is haunted by a paradox. As Margaret Davies explains the:

legitimate history of a legal system has a stopping point where the legality or illegality of a particular act is undecidable. For instance, a successful coup d'état is defined by the fact that an act which is illegal under the pre-existing legal order retrospectively becomes the source of all legality (Davies, 2001, p .225).

In order to provide itself with a foundation, and so remain the law, the law invokes self-evident truths, God, or appeals to natural law. The paradox is that the founding moment of the law is itself unfounded (Sokoloff, 2005, p. 343). Importantly this paradox does not only affect the origin of law. This is not an "exterior force which determines law, but rather a force internal to law'. Violence both founds and conserves a legal system. As Douzinas and Gearey observe 'Legal interpretations and judgements cannot be understood independently of this inescapable imbrication in violent action' (Douzinas \& Gearey, 2005, p. 71). So, for example, when the law is called upon to secure freedom of artistic expression in order to allow the critique of an existing social bond, reliance is placed on the law's authority and the grounds on which it is founded (Davies, 2001, p. 227). This would appear to create an impasse for those in such a position: either they rely on the existence of a legal system that is sought to be criticised or they allow the art to be censored. However, it seems to me that it is possible to locate the force of art in the process of opening that very situation.

The law's institutional response to the paradox brought about by iterability is to try and ensure that it is provided with a univocal interpretation that is received uniformly. It seems to me that SEC may be understood as one part of such an effort. In its provision of an archive of companies and directors it does not direct attention to the aporia of the law in the way that I have tried to suggest is done by They Rule. It is in opening the possibility of an engagement with the aporia that the force of the work is to be located. Once the violence of the law is acknowledged this opens up possibilities for the construction of a different society. Such a realisation provides 'a space for reconceptualising and reliving the relationship between homogenous law and the others which it presently excludes' (Davies, 2001, p. 228). My argument is that the force of They Rule is that it enables an engagement with the abyss underneath the foundation of all laws (Beardsworth, 1996, p. 25).

\section{CONCLUSION}

I have sought to argue, through an interpretation of the work They Rule, for an approach to art that employs data visualisation which goes beyond simply an engagement with work in terms of its content. To focus on the content of data is to emphasise the world in which the artwork is situated. In the context of They Rule this tends to happen at the cost of examining the process of how the work allows meaning to be constructed from data. This process of finding meaning is a function of the work's interface to its data. My argument has been that focussing on They Rule's interface invites attention be directed toward the (im)possibility of a legal system that can be both fair and equal for all and also able to make exceptions in specific cases. I have proposed that the force of such art lies in opening an awareness of the law's violence in the way it claims the authority to create and enforce laws that determine how such an aporia is to be resolved. An acknowledgement of its constructed nature unsettles claims to transcendence by the law, and so opens it to transformation by those it excludes.

\section{REFERENCES}

Attridge, D. (2004). The Singularity of Literature, Routledge, London and New York.

Beardsworth, R. (1996) Derrida and the Political. Routledge, London and New York.

Bednarzek, W. (2005) The Art and Promise of Nework Analysis. IEEE Multimedia, 12, no.3, pp. 19-21.

Davies, M. (2001) Derrida and law: legitimate fictions. In Cohen, T. (ed), Jacques Derrida and the Humanities: A Critical Reader. Cambridge University Press, Cambridge.

Derivart (2006) Derivatives, New Financial Art Visions.

http://www. derivart.info/index.php?s=derivados jos h\&lang=en (29 March 2010).

Derrida, J. (1988) Limited Inc. Northwestern University Press, Evanston, Illinois.

Derrida, J. (1990) 'Force of Law': The Mystical Foundation of Authority. Cardozo Law Review, 11, pp. 919-1045.

Derrida, J. (1992) Acts of Literature. Routledge, New York and London. 
Derrida, J. (2002) Acts of Religion. Routledge. New York and London.

Douzinas, C. and Gearey, A. (2005) Critical Jurisprudence: The Political Philosophy of Justice. Hart Publishing, Oxford and Portland, Oregon.

Gere, C. (2006) Art, Time and Technology. Berg, Oxford and New York.

Gere, C. and Corris, M. (2008) Non-relational Aesthetics. Artwords Press, London.

Greene, R (2004) Internet Art. Thames \& Hudson, London.

Griffis, R. (2004) The Climate Change Underground. http://rhizome.org/editorial/1249 (29 March 2010).

Ippolito, J. (2002) Ten Myths of Internet Art. Leonardo, 35, no. 5, pp. 485-498.

Johnstone, D. (2005). Webwork 4: They Rule. http://www.ciac.ca/magazine/archives/no 21/en/oe uvre4.htm (29 March 2010).

Kafka, F. (1994) The Trial. Penguin, London.

Lyotard, J.F. (1991) The Inhuman: Reflections on Time. Polity, Cambridge.

Manovich, L. (2001) The Language of New Media. MIT Press, Cambridge, Massachusetts.

Manovich, L. (2002) Data Visualisation as New Abstraction and Anti-Sublime. http://www.manovich.net/ (28 March 2010).

Miller, J.H. (2001) Derrida and literature. In Cohen, T. (ed), Jacques Derrida and the Humanities: A Critical Reader. Cambridge University Press, Cambridge.
On, J. (2004) They Rule http://www.theyrule.net/ (29 March 2010).

Paul, C. (2003) Digital Art. Thames \& Hudson, London.

Paul, C. (2007). The Database as System and Cultural Form: Anatomies of Cultural Narratives. In Vesna, V. (ed.), Database Aesthetics: Art in the Age of Information Overflow, University of Minnesota Press, Minneapolis and London.

Rokeby, D. (1995) Transforming Mirrors: Subjectivity and Control in Interactive Media. In Penny, S. (ed.), Critical Issues in Electronic Media, State University of New York Press, New York.

Sokoloff, W. W. (2005) Between Justice and Legality. Political Research Quarterly 58, no. 2, pp. 341-352.

Stalbaum, B. (2006) An Interpretative Framework for Contemporary Database Practice in the Arts.http://www.cityarts.com/paulc/database/databa se.html (28 March 2010)

Stallabrass, J. (2003) Internet Art: The Online Clash of Culture and Commerce. Tate Publishing, London.

United States Securities and Exchange

Commission. http://www.sec.gov/ (29 March 2010).

Whitney Artport (2002) Josh On \& Futurefarmers. http://artport.whitney.org/exhibitions/biennial2002/o n.shtml (29 March 2010).

Wolber, D. (2006) Political E-Identity: Campaign Funding Data and Beyond. In Proceedings of the 2006 International Conference on Digital Government Research, San Diego, California, 2124 May, pp. 29-37. ACM, New York. 